\title{
Structural transitions and unusual magnetic behavior in Mn-doped $\mathrm{Bi}_{1-\mathrm{x}} \mathrm{La}_{\mathrm{x}} \mathrm{FeO}_{3}$ perovskites
}

\author{
V. A. Khomchenko, ${ }^{1, a)}$ I. O. Troyanchuk, ${ }^{2}$ D. V. Karpinsky, ${ }^{3}$ S. Das, ${ }^{4}$ V. S. Amaral, ${ }^{4}$ M. Tovar, ${ }^{5}$ \\ V. Sikolenko, ${ }^{6}$ and J. A. Paixão ${ }^{1}$ \\ ${ }^{1}$ CEMDRX/Department of Physics, University of Coimbra, P-3004-516 Coimbra, Portugal \\ ${ }^{2}$ SSPA "Scientific-Practical Materials Research Centre of NAS of Belarus,” P. Brovka str. 19, 220072 Minsk, \\ Belarus \\ ${ }^{3}$ CICECO/Department of Materials and Ceramic Engineering, University of Aveiro, P-3810-193 Aveiro, \\ Portugal \\ ${ }^{4}$ CICECO/Department of Physics, University of Aveiro, P-3810-193 Aveiro, Portugal \\ ${ }^{5}$ Helmholtz-Zentrum-Berlin for Materials and Energy, D-14109 Berlin, Germany \\ ${ }^{6}$ Laboratory for Neutron Scattering, Paul Scherrer Institute, CH-5232 Villigen, Switzerland
}

(Received 15 May 2012; accepted 25 September 2012; published online 19 October 2012)

The effect of Mn doping on crystal structure and magnetic behavior of the polar antiferromagnetic and antipolar weak ferromagnetic phases of the $\mathrm{Bi}_{1-x} \mathrm{La}_{\mathrm{x}} \mathrm{FeO}_{3}$ system was investigated. Both reference compounds, $\mathrm{Bi}_{0.87} \mathrm{La}_{0.13} \mathrm{FeO}_{3}$ (space group $R 3 c$, tilting scheme $\left.\left(a^{-} a^{-} a^{-}\right)\right]$and $\mathrm{Bi}_{0.82} \mathrm{La}_{0.18} \mathrm{FeO}_{3}$ [space group Pnam, tilting scheme $\left(a^{-} a^{-} c^{+}\right) /\left(a^{-} a^{-} c^{-}\right)$], were shown to undergo the $\mathrm{Mn}$ doping induced structural phase transformation towards the average $\operatorname{Imma}\left(a^{-} b^{0} a^{-}\right)$ symmetry. Magnetization measurements performed for the compounds with the close to maximal manganese concentration $(y=0.4)$ found complex temperature-dependent behavior that can be indicative of a spin-reorientation transition. Enhanced spontaneous magnetization characteristic of the Mn-enriched $x=0.13$ and $x=0.18$ samples at low temperature is consistent with a competitive character of the superexchange interactions peculiar to the $\mathrm{Fe} / \mathrm{Mn}$ containing perovskite systems. (C) 2012 American Institute of Physics. [http://dx.doi.org/10.1063/1.4759435]

\section{INTRODUCTION}

Bismuth ferrite, $\mathrm{BiFeO}_{3}$, remains the only material with the proven multiferroic behavior far above the room temperature. ${ }^{1}$ The compound crystallizes in the noncentrosymmetric rhombohedral structure (space group $R 3 c$ ) compatible with the polar ionic displacements along the main hexagonal axis [001] $\left(\mathrm{T}_{\mathrm{C}} \approx 1100 \mathrm{~K}\right)$. Magnetic moments of $\mathrm{Fe}^{3+}$ ions form the $G$-type antiferromagnetic structure (stands for an isotropic antiferromagnetic coupling of a given atom with the six magnetic neighbors) with $\mathrm{T}_{\mathrm{N}} \approx 640 \mathrm{~K}$. Theoretically, symmetry of the space group $R 3 c$ permits existence of a weak ferromagnetism (if the sublattice magnetizations are oriented perpendicular to the [001] axis $^{2}$ ). However, the weak ferromagnetism is not observed in practice, because the antiferromagnetic order is modulated by a long-range ( $\sim 620 \AA$ ) cycloid. ${ }^{3}$ Possibility to tune and control the multiferroic behavior of $\mathrm{BiFeO}_{3}$ via a chemical substitution motivated numerous investigations of the lanthanide $(L n)$ and transition metal $(M e)$ doped compounds. A-site La substitution, for instance, induces transition from the initial antiferromagnetic polar rhombohedral $R 3 c$ phase to the weak ferromagnetic antipolar orthorhombic Pnam phase (stable in a very narrow compositional range near $x=0.18){ }^{4,5}$ The latter, in turn, transforms into the weak ferromagnetic antipolar phase with an incommensurately modulated structure (super-

\footnotetext{
a) Author to whom correspondence should be addressed. Electronic mail: uladzimir@fis.uc.pt. Telephone: +351 239410 637. Fax: +351 239829 158.
}

space group $\operatorname{Imma}(00 \gamma) s 00)$; the single-phase state is realized at $0.19 \leq x \leq 0.30 .{ }^{4}$ A single weak ferromagnetic nonpolar orthorhombic Pnma phase characteristic of $\mathrm{LaFeO}_{3}$ orthoferrite is formed at $x \geq 0.5$. ${ }^{4}$ The structural and magnetic phase transformations occur via realization of the intermediate two-phase states. ${ }^{4,5}$ Unlike $\mathrm{Bi}_{1-\mathrm{x}} L n_{\mathrm{x}} \mathrm{FeO}_{3}$ series, permitting the solid-state synthesis of the perovskite phases at ambient pressure, $\mathrm{BiFe}_{1-\mathrm{y}} \mathrm{Me}_{\mathrm{y}} \mathrm{O}_{3}$ solid solutions can be obtained only in a limited compositional range. In particular, the singlephase $\mathrm{BiFe}_{1-\mathrm{y}} \mathrm{Mn}_{\mathrm{y}} \mathrm{O}_{3}$ compounds can be synthesized only for $y \leq 0.3{ }^{6} \mathrm{Mn}$ substitution was not found to alter the space group of $\mathrm{BiFeO}_{3}$ for $y \leq 0.3$. However, significant decrease of the ferroelectric and magnetic transition temperatures (around $6{ }^{\circ} \mathrm{C}$ per $1 \% \mathrm{Mn}$ ) was revealed with increasing $\mathrm{Mn}$ concentration. ${ }^{6}$ The manganese containing perovskites easily accommodate superstoichiometric oxygen, charge balance being achieved by the partial oxidation of $\mathrm{Mn}^{3+}$ to $\mathrm{Mn}^{4+}$. Effect of a simultaneous Ln and Mn substitution on the crystal structure and multiferroic properties of $\mathrm{BiFeO}_{3}$ was also recently studied. ${ }^{7,8}$ Investigation of the $\mathrm{Bi}_{1-\mathrm{x}} \mathrm{Pr}_{\mathrm{x}}(\mathrm{Fe}, \mathrm{Mn}) \mathrm{O}_{3}$ and $\mathrm{Bi}_{1-\mathrm{x}} \mathrm{Sm}_{\mathrm{x}}(\mathrm{Fe}, \mathrm{Mn}) \mathrm{O}_{3}$ series showed that both initial polar rhombohedral $(R 3 c)$ and intermediate antipolar orthorhombic (Pnam) structures characteristic of the low-doped $\mathrm{Bi}_{1-\mathrm{x}} \operatorname{Ln}_{\mathrm{x}} \mathrm{FeO}_{3}{ }^{9-12}$ can be effectively modified by Mn substitution to stabilize the new phases either demonstrating the traits of incommensurability or possessing the nonpolar Pnma structure. ${ }^{7,8}$ Magnetic behavior of the Mn-containing samples changes in correlation with evolution of their structural state. Within compositional range of the rhombohedrally distorted compounds, the manganese substitution gives rise to suppression 
of the dominant antiferromagnetic interaction. In the dopinginduced phases, a gradual decreasing the room temperature spontaneous magnetization takes place with increasing $\mathrm{Mn}$ content. $^{7,8}$ In this paper, we continue to investigate the effect of the simultaneous lanthanide/manganese doping and report on properties of the $\mathrm{Bi}_{0.87} \mathrm{La}_{0.13} \mathrm{Fe}_{1-\mathrm{y}} \mathrm{Mn}_{\mathrm{y}} \mathrm{O}_{3}$ and $\mathrm{Bi}_{0.82} \mathrm{La}_{0.18} \mathrm{Fe}_{1-\mathrm{y}} \mathrm{Mn}_{\mathrm{y}} \mathrm{O}_{3}$ compounds (the $A$-site content was chosen in order to follow the Mn-driven structural and magnetic phase evolution for both the initial $R 3 \mathrm{C}$ and Pnam phases ${ }^{4,5}$ ) with $y$ approaching the manganese solid solubility limit.

\section{EXPERIMENTAL}

Ceramic samples $\mathrm{Bi}_{1-\mathrm{x}} \mathrm{La}_{\mathrm{x}} \mathrm{Fe}_{1-\mathrm{y}} \mathrm{Mn}_{\mathrm{y}} \mathrm{O}_{3}(x=0.13,0.18$; $y \leq 0.4$ ) were prepared by a conventional solid-state reaction method using the high-purity oxides $\mathrm{Bi}_{2} \mathrm{O}_{3}, \mathrm{La}_{2} \mathrm{O}_{3}$ (annealed at $\left.1000{ }^{\circ} \mathrm{C}\right), \mathrm{Fe}_{2} \mathrm{O}_{3}$, and $\mathrm{Mn}_{2} \mathrm{O}_{3}$ taken in stoichiometric cation ratio and thoroughly mixed using a planetary mill (Retsch). The synthesis was carried out in air in a temperature range $900-950^{\circ} \mathrm{C}$ for $15 \mathrm{~h}$ (annealing temperature was decreased with increasing Mn content). Oxygen content in Mn-containing samples was determined by thermogravimetric analysis in a reducing $\mathrm{N}_{2}$ flow. The compounds were found to be overstoichiometric with $\delta$ varying from $0.01(1)$ to $0.02(1)$. X-ray diffraction (XRD) patterns were collected at room temperature using DRON-3M and Rigaku D/MAXB diffractometers with $\mathrm{Cu} \mathrm{K}_{\alpha}$ radiation. Neutron diffraction (ND) spectra were obtained using a fine resolution neutron powder diffractometer E9 (Firepod) with a neutron wavelength $\lambda=1.7977 \AA$ at the Berlin Neutron Scattering Center of Helmholtz-Zentrum Berlin and a high-resolution powder diffractometer for thermal neutrons HRPT $(\lambda=1.494 \AA)$ at the Laboratory for Neutron Scattering of the Paul Scherrer Institute. XRD and ND data were analyzed by the Rietveld method using the FULLPROF program. ${ }^{13}$ Magnetic properties of the samples were characterized with a vibrating sample magnetometer (Cryogenic Instruments) in the temperature range from $5 \mathrm{~K}$ to $320 \mathrm{~K}$ and magnetic fields up to $10 \mathrm{~T}$.

\section{RESULTS AND DISCUSSION}

Neutron powder diffraction pattern obtained for the $\mathrm{Bi}_{0.87} \mathrm{La}_{0.13} \mathrm{FeO}_{3}$ compound at room temperature was successfully fitted using the antiferromagnetic rhombohedral (space group $R 3 c$ ) model (Fig. 1). With respect to the cubic $P m \overline{3} m$ lattice characteristic of an ideal $A B \mathrm{O}_{3}$ perovskite, structural distortions in $\mathrm{Bi}_{0.87} \mathrm{La}_{0.13} \mathrm{FeO}_{3}$ can be described in terms of the antiphase tilt of the adjacent $\mathrm{BO}_{6}$ octahedra $\left(a^{-} a^{-} a^{-}\right.$tilt system in Glazer's notation $\left.{ }^{14}\right)$ and the polar ionic displacements along the $[111]_{\mathrm{C}}$ direction of the primary cubic cell (Fig. 1). The refined structural parameters are summarized in Table I. Though ordering of the $\mathrm{Fe}^{3+}$ magnetic moments in the rhombohedral phase is expected to be modulated with a long period, ${ }^{15}$ the magnetic satellite peaks were not resolved in the present diffraction experiment. In the first approximation, magnetic contribution to the ND pattern was described by assuming an antiferromagnetic $G$-type ordering of $\mathrm{Fe}^{3+}$ magnetic moments $\left(3.64(3) \mu_{\mathrm{B}}\right)$ with an arbitrary direction taken along the hexagonal $c$ axis. Another refer-
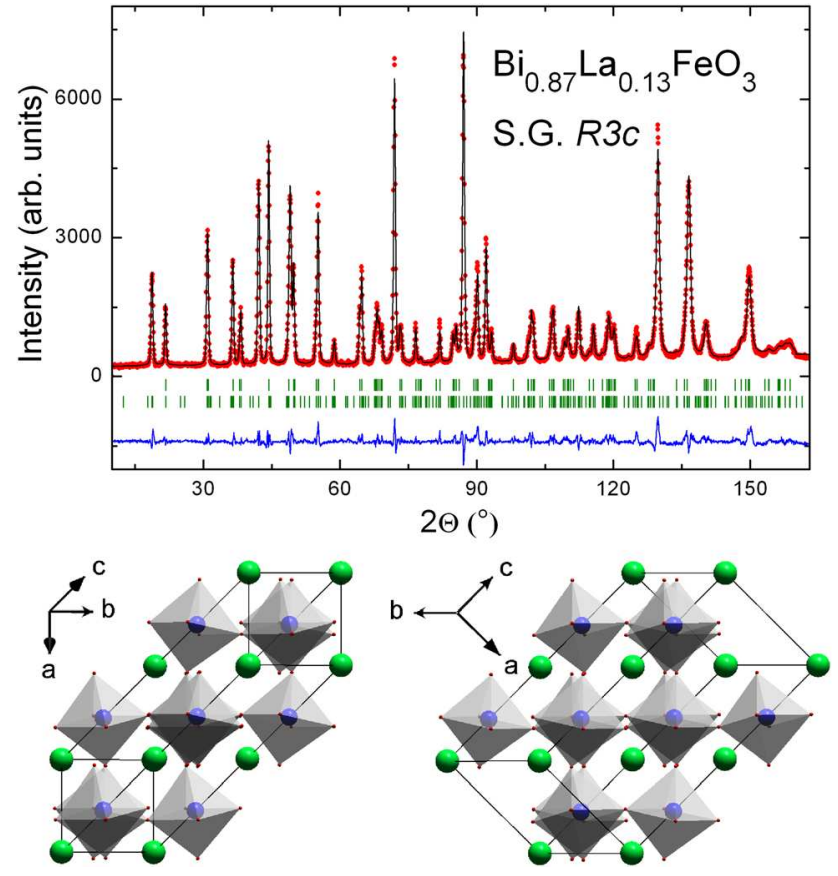

FIG. 1. Observed, calculated, and difference ND patterns $(\lambda=1.494 \AA)$ for $\mathrm{Bi}_{0.87} \mathrm{La}_{0.13} \mathrm{FeO}_{3}$ compound at room temperature and schematic view of the corresponding unit cell along the two mutually perpendicular axes coincident with the $\langle 100\rangle$ directions of the parent cubic perovskite cell.

ence compound, $\mathrm{Bi}_{0.82} \mathrm{La}_{0.18} \mathrm{FeO}_{3}$, was confirmed to possess the orthorhombic Pnam structure combining the modulated $\left(a^{-} a^{-} c^{+}\right) /\left(a^{-} a^{-} c^{-}\right)$octahedral tilting with the $\mathrm{PbZrO}_{3}$-like antipolar displacements of the $A$-site cations along the [110/ $\overline{1} \overline{1} 0]_{\mathrm{C}}$ directions of the parent perovskite cell (Fig. 2, Table I). The magnetic moments of iron ions $\left(\mu_{\mathrm{Fe}}=3.64(3) \mu_{\mathrm{B}}\right)$ are aligned along the $c$ axis of the orthorhombic cell and form the $G$-type antiferromagnetic structure.

Light manganese doping of the reference $\mathrm{Bi}_{1-x} \mathrm{La}_{x} \mathrm{FeO}_{3}$ solid solutions results in structural changes very similar to those found in isostructural $\mathrm{Bi}_{0.89} \mathrm{Pr}_{0.11} \mathrm{FeO}_{3}$ (S.G. R3c) and $\mathrm{Bi}_{0.84} \mathrm{Pr}_{0.16} \mathrm{FeO}_{3}$ (S.G. Pnam) compounds upon the $B$-site substitution. ${ }^{7}$ In particular, both initial phases undergo the composition-driven structural transformation to the phase, whose typical diffraction pattern is composed of the basic perovskite reflections fully compatible with the $\sqrt{2} a_{c} \times 2 a_{c} \times \sqrt{ } 2 a_{c}$ orthorhombic unit cell and the small superlattice reflexions inconsistent with any multiple supercell (Fig. 3). The same picture was earlier found upon the XRD and neutron powder diffraction study of the $\mathrm{Bi}_{1-x} \mathrm{La}_{x} \mathrm{FeO}_{3}(0.2<x<0.5)$ perovskites. ${ }^{5}$ It was suggested that the observed features could be associated with a modulation of the $\mathrm{PbZrO}_{3}$-like antipolar order. ${ }^{5}$ Simultaneous electron microscopy and synchrotron $\mathrm{x}$-ray diffraction investigations confirmed the formation of an incommensurately modulated structure with the superspace group Imma $(00 \gamma) s 00 .{ }^{4}$ Complete identification of crystal structure of the Mn doping-induced phase (which stabilizes at $y>0.1$ for $x=0.13$ and at $y>0$ for $x=0.18$ ) can hardly be adequately performed in the framework of the available $\mathrm{x}$-ray diffraction experiment, so this issue remains a matter of future research.

Intensity of the reflections preliminary considered as originating from the modulated antipolar ionic displacements 
TABLE I. Structural parameters for the $\mathrm{Bi}_{1-x} \mathrm{La}_{\mathrm{x}} \mathrm{Fe}_{1-\mathrm{y}} \mathrm{Mn}_{\mathrm{y}} \mathrm{O}_{3}$ compounds at room temperature.

\begin{tabular}{|c|c|c|c|c|c|c|c|c|}
\hline $\begin{array}{l}\text { Composition } \\
\text { space group }\end{array}$ & Cell $(\AA)$ & Atom & Site & $\mathrm{x}$ & $\mathrm{y}$ & $\mathrm{z}$ & $\mathrm{U}_{\text {iso }} \times 100\left(\AA^{2}\right)$ & $\mathrm{R}$-factors (\%) \\
\hline \multirow{6}{*}{$x=0.13, y=0 R 3 c$} & \multirow{6}{*}{$\begin{array}{c}a=5.57933(1) \\
c=13.79668(2)\end{array}$} & $\mathrm{Bi} / \mathrm{La}$ & $6 a$ & 0 & 0 & 0 & $1.20(4)$ & \multirow{7}{*}{$\begin{array}{c}\mathrm{R}_{\mathrm{p}}=5.95 \\
\mathrm{R}_{\mathrm{wp}}=7.43 \\
\mathrm{R}_{\mathrm{B}}=3.90 \\
\mathrm{R}_{\mathrm{mag}}=4.17\end{array}$} \\
\hline & & $\mathrm{Fe}$ & $6 a$ & 0 & 0 & $0.22289(20)$ & $0.71(4)$ & \\
\hline & & $\mathrm{O}$ & $18 \mathrm{~b}$ & $0.4426(5)$ & $0.0139(6)$ & $0.9579(3)$ & $1.13(3)$ & \\
\hline & & $\mathrm{Bi} / \mathrm{La} 1$ & $8 d$ & $0.206(2)$ & $0.3713(12)$ & $0.0013(13)$ & $1.6(3)$ & \\
\hline & & $\mathrm{Bi} / \mathrm{La} 2$ & $4 c$ & $0.218(6)$ & $0.366(2)$ & 0.25 & $2.1(6)$ & \\
\hline & & $\mathrm{Bi} / \mathrm{La} 3$ & $4 c$ & $0.792(6)$ & $0.625(2)$ & 0.25 & $2.1(6)$ & \\
\hline \multirow{9}{*}{$\begin{array}{l}x=0.18, y=0 \\
\text { Pnam }\end{array}$} & \multirow{9}{*}{$\begin{array}{c}a=5.58891(3) \\
b=11.22664(4) \\
c=15.60876(4)\end{array}$} & $\mathrm{Fe} 1$ & $8 \mathrm{~d}$ & $0.761(2)$ & $0.8768(13)$ & $0.1246(9)$ & $0.7(2)$ & \\
\hline & & $\mathrm{Fe} 2$ & $8 \mathrm{~d}$ & $0.761(2)$ & $0.8770(13)$ & $0.6241(10)$ & $0.7(2)$ & \multirow{8}{*}{$\begin{array}{c}\mathrm{R}_{\mathrm{p}}=4.29 \\
\mathrm{R}_{\mathrm{wp}}=5.62 \\
\mathrm{R}_{\mathrm{B}}=6.42 \\
\mathrm{R}_{\mathrm{mag}}=4.53\end{array}$} \\
\hline & & $\mathrm{O} 1$ & $8 \mathrm{~d}$ & $0.287(3)$ & $0.1605(15)$ & $0.9992(17)$ & $1.3(3)$ & \\
\hline & & $\mathrm{O} 2$ & $4 c$ & $0.292(9)$ & $0.085(4)$ & 0.25 & $2.1(8)$ & \\
\hline & & $\mathrm{O} 3$ & $8 \mathrm{~d}$ & $0.002(8)$ & 0.999(3) & $0.1117(13)$ & $1.8(4)$ & \\
\hline & & $\mathrm{O} 4$ & $8 \mathrm{~d}$ & $0.507(5)$ & $0.996(3)$ & $0.0954(9)$ & $1.1(2)$ & \\
\hline & & O5 & $4 c$ & $0.300(7)$ & $0.095(3)$ & 0.75 & $1.5(6)$ & \\
\hline & & O6 & $8 \mathrm{~d}$ & $0.525(4)$ & $0.245(2)$ & $0.1493(16)$ & $1.4(4)$ & \\
\hline & & $\mathrm{O} 7$ & $8 d$ & $0.564(3)$ & $0.2248(18)$ & $0.6379(11)$ & $1.2(3)$ & \\
\hline \multirow{6}{*}{$\begin{array}{l}x=0.18, y=0.4 \\
\text { Imma }\end{array}$} & & $\mathrm{Bi} / \mathrm{La}$ & $4 e$ & 0 & 0.25 & $0.9897(6)$ & $2.18(5)$ & \multirow{5}{*}{$\begin{array}{l}\mathrm{R}_{\mathrm{p}}=7.22 \\
\mathrm{R}_{\mathrm{wp}}=9.7 \\
\mathrm{R}_{\mathrm{B}}=8.24\end{array}$} \\
\hline & $a=5.58967(5)$ & $\mathrm{Fe} / \mathrm{Mn}$ & $4 b$ & 0 & 0 & 0.5 & $1.12(8)$ & \\
\hline & $b=7.79109(6)$ & $\mathrm{O} 1$ & $4 \mathrm{e}$ & 0.5 & 0.25 & $0.080(5)$ & $1.3(5)$ & \\
\hline & $c=5.60309(5)$ & $\mathrm{O} 2$ & $8 \mathrm{~g}$ & 0.25 & $0.525(3)$ & 0.25 & $1.8(4)$ & \\
\hline & & $\mathrm{Bi} / \mathrm{La}$ & $4 c$ & $0.0074(5)$ & 0.25 & $0.9927(5)$ & $1.98(4)$ & \\
\hline & $a=5.57080(3)$ & $\mathrm{Fe} / \mathrm{Mn}$ & $4 b$ & 0 & 0 & 0.5 & $0.94(5)$ & \multirow{3}{*}{$\begin{array}{c}\mathrm{R}_{\mathrm{p}}=6.43 \\
\mathrm{R}_{\mathrm{wp}}=8.49 \\
\mathrm{R}_{\mathrm{B}}=6.03\end{array}$} \\
\hline \multirow{2}{*}{$\begin{array}{l}x=0.4, y=0.4 \\
\text { Pnma }\end{array}$} & $b=7.83016(4)$ & $\mathrm{O} 1$ & $4 c$ & $0.483(6)$ & 0.25 & $0.063(4)$ & $1.8(5)$ & \\
\hline & $c=5.55590(3)$ & $\mathrm{O} 2$ & $8 \mathrm{~d}$ & $0.237(4)$ & $0.5418(15)$ & $0.211(4)$ & $1.3(4)$ & \\
\hline
\end{tabular}

gradually decreases with increasing Mn content. However, even in $y=0.4$ samples (having the concentration of manganese slightly exceeding its solid solubility limit in the $\mathrm{Bi}_{1-\mathrm{x}} \mathrm{La}_{\mathrm{x}} \mathrm{Fe}_{1-\mathrm{y}} \mathrm{Mn}_{\mathrm{y}} \mathrm{O}_{3}(x=0.13,0.18)$ series $)$ traces of some of these reflections can still be detected in form of the very
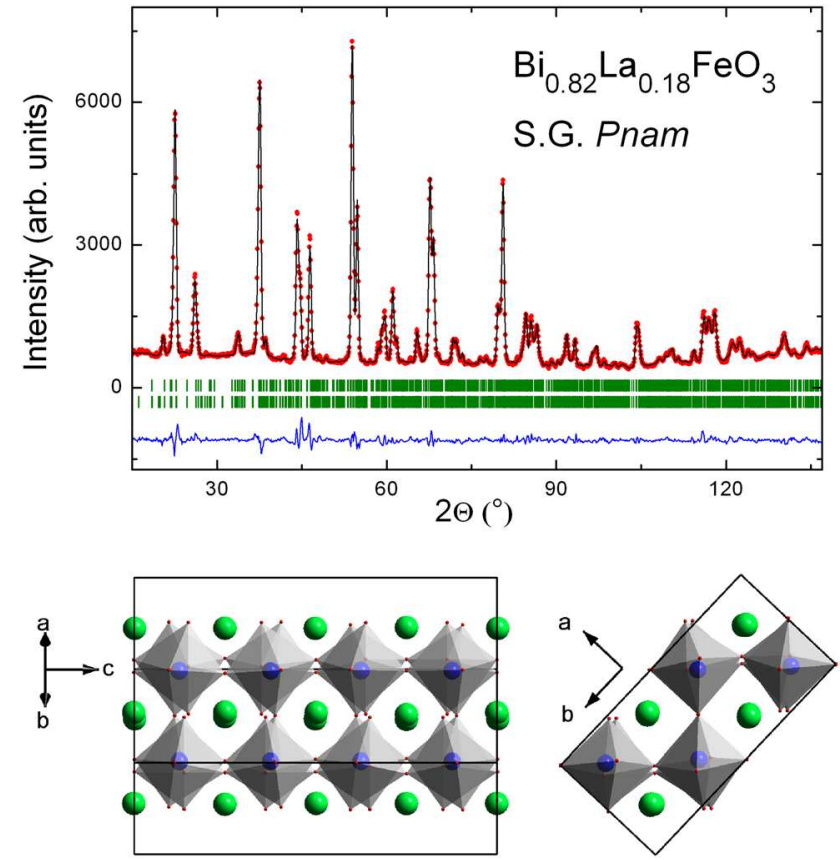

FIG. 2. Observed, calculated, and difference ND patterns $(\lambda=1.7977 \AA)$ for $\mathrm{Bi}_{0.82} \mathrm{La}_{0.18} \mathrm{FeO}_{3}$ compound at room temperature and schematic view of the corresponding unit cell along the two mutually perpendicular axes coincident with the $\langle 100\rangle$ directions of the parent cubic perovskite cell. broad diffuse peaks presented on the background level. Such a picture is consistent with existence of the local inclusions (retaining structural motif more typical of the lightly doped $(\mathrm{Bi}, \mathrm{La}) \mathrm{Fe}_{1-\mathrm{y}} \mathrm{Mn}_{\mathrm{y}} \mathrm{O}_{3}$ samples) within the average structure characteristic of the heavily substituted compounds. Further analysis of the XRD patterns showed that the average crystal structure of the $y=0.4$ samples could not be compatible with an inphase octahedral tilting: the superstructure reflections $1 / 2(h k l ; \quad h=2 n, \quad k, l=2 n+1, \quad k \neq l), \quad 1 / 2(h k l ; \quad k=2 n$,

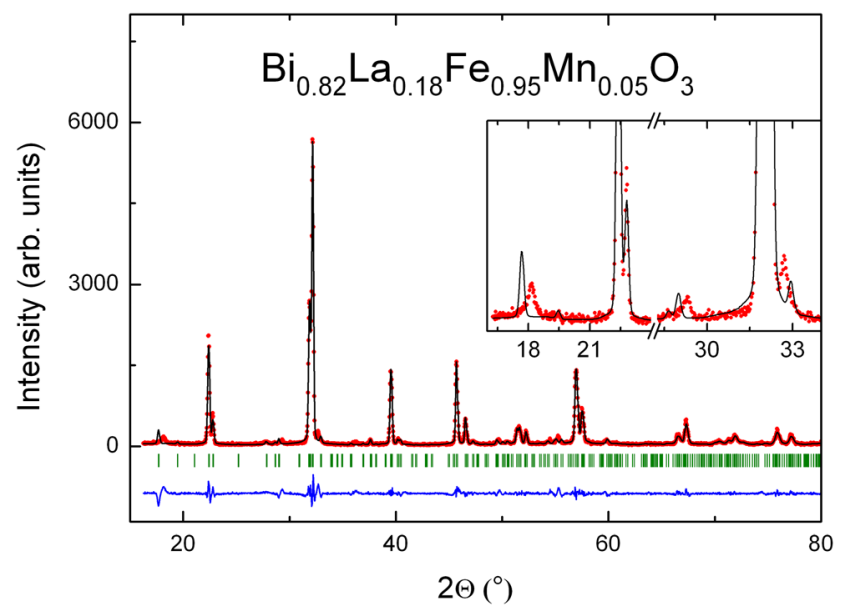

FIG. 3. XRD patterns for $\mathrm{Bi}_{0.82} \mathrm{La}_{0.18} \mathrm{Fe}_{0.95} \mathrm{Mn}_{0.05} \mathrm{O}_{3}$ compound fitted in approximation of the simplified commensurate structural model combining $\left(a^{-} a^{-} c^{0}\right)$ octahedral tilting with $\mathrm{PbZrO}_{3}$-type antipolar displacements (space group Pbam). Inset shows enlarged part of the corresponding spectra to demonstrate insufficient agreement of the theoretical peaks with the experimental pattern. 
$h, l=2 n+1, h \neq l)$, and $1 / 2(h k l ; l=2 n, h, k=2 n+1, h \neq k)$ associated with the $a^{+}, b^{+}$, and $c^{+}$tilting components ${ }^{14}$ were not detected in the diffraction spectra. At the same time, the superstructure reflections originating from both the antiphase tilting and antiparallel $A$-site ionic displacements ${ }^{14}$ were confirmed to exist. Taking into account the restriction on the tilting configurations, structural model consistent with the most high-symmetry antiphase tilt system $a^{0} a^{0} c^{-}$(corresponds to the space group $I 4 / \mathrm{mcm}^{14}$ ) was then tested. It was found that a number of diffraction peaks could not be indexed in the tetragonal system with the unit cell parameters $a \approx \sqrt{2} a_{c}$ and $c \approx 2 a_{c}$ (in particular, simultaneous fulfilment of the conditions $k=2 n$ and $l=2 n$ for $(0 k l)$ reflection and $h=2 n$ and $l=2 n$ for $(h 0 l)$ reflection could not be ensured), so symmetry of the possible tilting configuration was further reduced to the Glazer's tilt system $a^{-} b^{0} a^{-}$(space group Imma). ${ }^{14}$ Rietveld refinement of the corresponding model gave a reasonably good agreement between the experimental and theoretical diffraction patterns (Fig. 4). Apart from the several mentioned broad peaks having the background-level intensity insufficient to be considered in the resulting structural model, no additional reflections clearly indicative of the necessity to reduce the average structural symmetry of the samples were revealed. Refined parameters of the structural model for the $x=0.18$ compound are shown in Table I.

Thus, the undertaken structural investigation of the $\mathrm{Bi}_{1-\mathrm{x}} \mathrm{La}_{\mathrm{x}} \mathrm{Fe}_{1-\mathrm{y}} \mathrm{Mn}_{\mathrm{y}} \mathrm{O}_{3}(x=0.13,0.18 ; y \leq 0.4)$ compounds shows that both polar [R3c $\left.\left(a^{-} a^{-} a^{-}\right)\right]$and antipolar [Pnam $\left.\left(a^{-} a^{-} c^{+}\right) /\left(a^{-} a^{-} c^{-}\right)\right]$structures characteristic of the $B$-site undoped La-substituted samples undergo the Mn doping induced phase transformation towards the average Imma $\left(a^{-} b^{0} a^{-}\right)$symmetry. The transformation occurs via the formation of an intermediate structural phase, whose preliminary analysis reveals the regularities formerly reported for
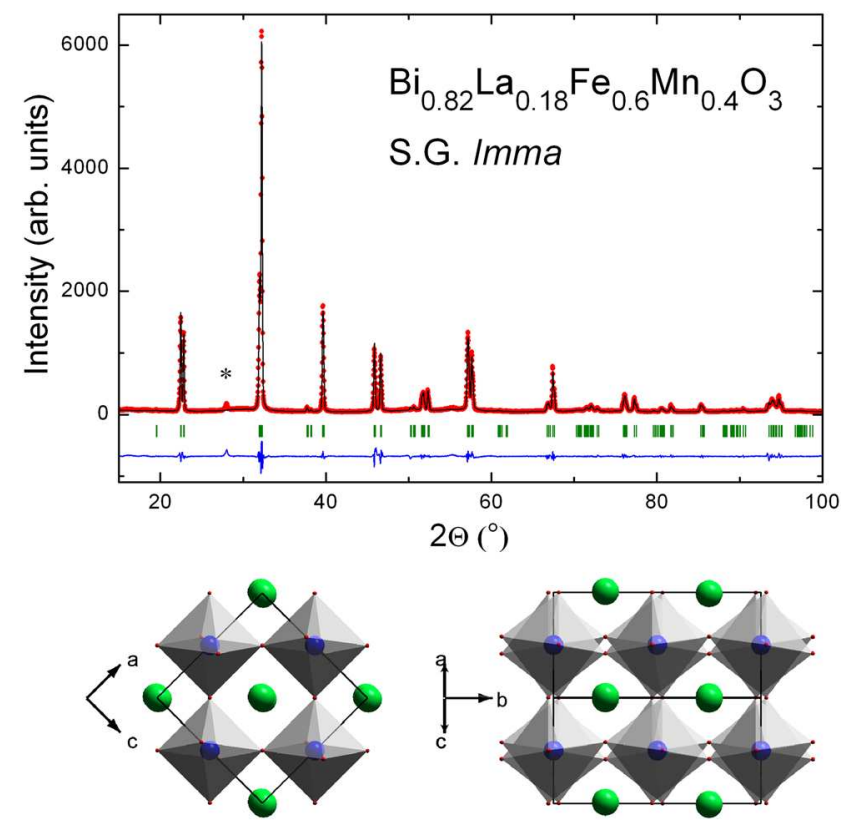

FIG. 4. Observed, calculated, and difference XRD patterns for $\mathrm{Bi}_{0.82} \mathrm{La}_{0.18-}$ $\mathrm{Fe}_{0.6} \mathrm{Mn}_{0.4} \mathrm{O}_{3}$ compound at room temperature (peak from impurity phase $\mathrm{Bi}_{25}(\mathrm{Fe}, \mathrm{Mn}) \mathrm{O}_{39}$ is marked by asterisk) and schematic view of the corresponding unit cell. the $\mathrm{Bi}_{1-\mathrm{x}} \mathrm{La}_{\mathrm{x}} \mathrm{FeO}_{3}$ compounds possessing the incommensurately modulated antipolar structure ${ }^{4,5}$ with the superspace group $\operatorname{Imma}(00 \gamma) s 00$. It is interesting to note that despite the opposite influence of the $A$-site $\mathrm{La}^{3+}$ and $B$-site $\mathrm{Mn}^{3+} / \mathrm{Mn}^{4+}$ doping of $\mathrm{BiFeO}_{3}$ on the Goldschmidt tolerance factor $t=$ $\frac{r_{A}+r_{O}}{\sqrt{2}\left(r_{B}+r_{O}\right)}$ determining the degree of distortion in perovskites $\left(r_{A}, r_{B}\right.$, and $r_{O}$ are the ionic radii of $A, B$, and $\mathrm{O}$ ions; $\left.r_{L a^{3+}}<r_{B i^{3+}}, r_{\left\langle M n^{3+} / M n^{4+}\right\rangle}<r_{F e^{3+}}\right)$, structural phase evolution in $\mathrm{Bi}_{1-x} \mathrm{La}_{\mathrm{x}} \mathrm{FeO}_{3}$ and $\mathrm{Bi}_{1-\mathrm{x}} \mathrm{La}_{\mathrm{x}} \mathrm{Fe}_{1-\mathrm{y}} \mathrm{Mn}_{\mathrm{y}} \mathrm{O}_{3}(x=0.13,0.18$; $y \leq 0.4)$ series follows the same scenario. Indeed, La substitution also suppresses the rhombohedral polar structure peculiar to pure $\mathrm{BiFeO}_{3}$ to stabilize the orthorhombic incommensurate phase with the average $a^{-} b^{0} a^{-}$tilting scheme. ${ }^{4}$ This observation is consistent with the structural behavior of some other $\mathrm{La} / \mathrm{Mn}$ co-substituted series. In particular, complementary XRD measurements carried out for the $\mathrm{Bi}_{1-\mathrm{x}} \mathrm{La}_{\mathrm{x}} \mathrm{Fe}_{0.6} \mathrm{Mn}_{0.4} \mathrm{O}_{3} \quad(0.25 \leq x \leq 0.4) \quad$ compounds show that the samples possess the dominant Pnma $\left(a^{-} b^{+} a^{-}\right)$structure (Fig. 5, Table I) characteristic of the $\mathrm{Bi}_{1-x} \mathrm{La}_{x} \mathrm{FeO}_{3}$ series only above $x=0.5{ }^{4}$ So, under certain conditions, $B$-site $\mathrm{Mn}$ and $A$-site La doping can affect the crystal structure of $\mathrm{BiFeO}_{3}$ in the same way. In unison with this statement, recent investigations of Belik et al. ${ }^{16}$ showed that the antipolar orthorhombic Pnam structure which was realized in the $\mathrm{Bi}_{1-\mathrm{x}} \mathrm{La}_{\mathrm{x}} \mathrm{FeO}_{3}$ system at $x=0.18$ could be stabilized in the $A$-site undoped $\mathrm{BiFe}_{1-\mathrm{y}} \mathrm{Mn}_{\mathrm{y}} \mathrm{O}_{3}(0.2 \leq y \leq 0.6)$ compounds synthesized under high-pressure (see also Ref. 17). Reasons of the Mn-doping induced or high-pressure stabilized structural transformations in $\mathrm{Bi}_{1-\mathrm{x}} \mathrm{La}_{\mathrm{x}}(\mathrm{Fe}, \mathrm{Mn}) \mathrm{O}_{3}$ should be related to the complex interplay of the structural distorsions associated with the stereochemical activity of $6 s^{2}$ lone pairs of the $\mathrm{Bi}^{3+}$ ions and rotations of $\langle\mathrm{Fe}, \mathrm{Mn}\rangle \mathrm{O}_{6}$ octahedra. ${ }^{18-20}$ It is worth noting that both homovalent $\mathrm{Mn}^{3+}$ and heterovalent $\mathrm{Mn}^{3+} / \mathrm{Mn}^{4+}$ doping of bismuth ferrite $\left(r_{\mathrm{Mn}^{3+}}=r_{\mathrm{Fe}^{3+}}\right.$
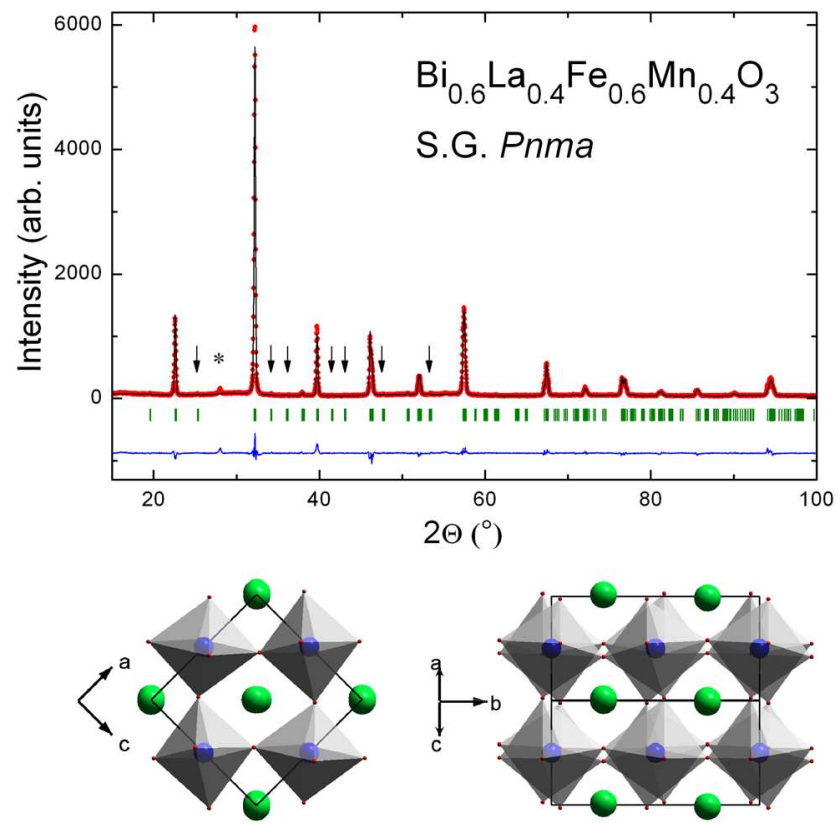

FIG. 5. Observed, calculated, and difference XRD patterns for $\mathrm{Bi}_{0.6} \mathrm{La}_{0.4}$ $\mathrm{Fe}_{0.6} \mathrm{Mn}_{0.4} \mathrm{O}_{3}$ compound at room temperature and schematic view of the corresponding unit cell. Peak from impurity phase $\mathrm{Bi}_{25}(\mathrm{Fe}, \mathrm{Mn}) \mathrm{O}_{39}$ is marked by asterisk. Characteristic reflections forbidden by the space group Imma and indicating necessity of the symmetry lowering are marked by arrows. 
$=0.645 \AA ; r_{M n^{4+}}=0.53 \AA^{21}$ ) identically affect the ferroelectric transition temperature of the polar $\mathrm{BiFe}_{1-\mathrm{y}} \mathrm{Mn}_{\mathrm{y}} \mathrm{O}_{3+\delta}$ solid solutions prepared at ambient pressure: the Curie temperature decreases with a close to constant rate of 5 to $6{ }^{\circ} \mathrm{C}$ per $1 \% \mathrm{Mn}$ weakly depending on oxygen stoichiometry of the samples. ${ }^{6}$ Accordingly, one can suppose that lattice instability driven by substitution with the ions possessing a different ionic radius is not the only factor determining the unusual structural behavior in $\mathrm{Mn}$-doped $\mathrm{BiFeO}_{3}$-based compounds and possible influence of the Jahn-Teller distorsions associated with the presence of $\mathrm{Mn}^{3+}$ ions in the host lattice should also be taken into account.

Having been consistent with the phase diagram of the $\mathrm{BiFe}_{1-\mathrm{y}} \mathrm{Mn}_{\mathrm{y}} \mathrm{O}_{3}$ system suggesting 6 to $7^{\circ} \mathrm{C}$ per $1 \% \mathrm{Mn}$ decreasing rate of the magnetic phase transition temperature, ${ }^{6}$ the $\mathrm{Bi}_{1-x} \mathrm{La}_{x} \mathrm{Fe}_{0.6} \mathrm{Mn}_{0.4} \mathrm{O}_{3}(x=0.13,0.18)$ compounds are magnetically ordered at room temperature as confirmed by existence of the small remanence $\left(\mathrm{M}_{\mathrm{r}} \approx 0.03 \mathrm{emu} / \mathrm{g}\right)$ in the corresponding field dependences of the magnetization (Fig. 6(a)). At $\mathrm{T}=5 \mathrm{~K}$, the spontaneous magnetization as extracted from the linear extrapolation of the high field magnetization to $\mathrm{H}=0$ reaches $3.2 \mathrm{emu} / \mathrm{g}$ for $x=0.13$ and $4 \mathrm{emu} / \mathrm{g}$ for 0.18 (Fig. 6(b)). These values are an order of magnitude higher than those typical of the weak ferromagnetic phase of the $\mathrm{Bi}_{1-x} \mathrm{La}_{\mathrm{x}} \mathrm{FeO}_{3}$ compounds at the same temperature ${ }^{4}$ thus implying that Dzyaloshinsky-Moriya interaction $^{22,23}$ cannot be considered as the only factor re-

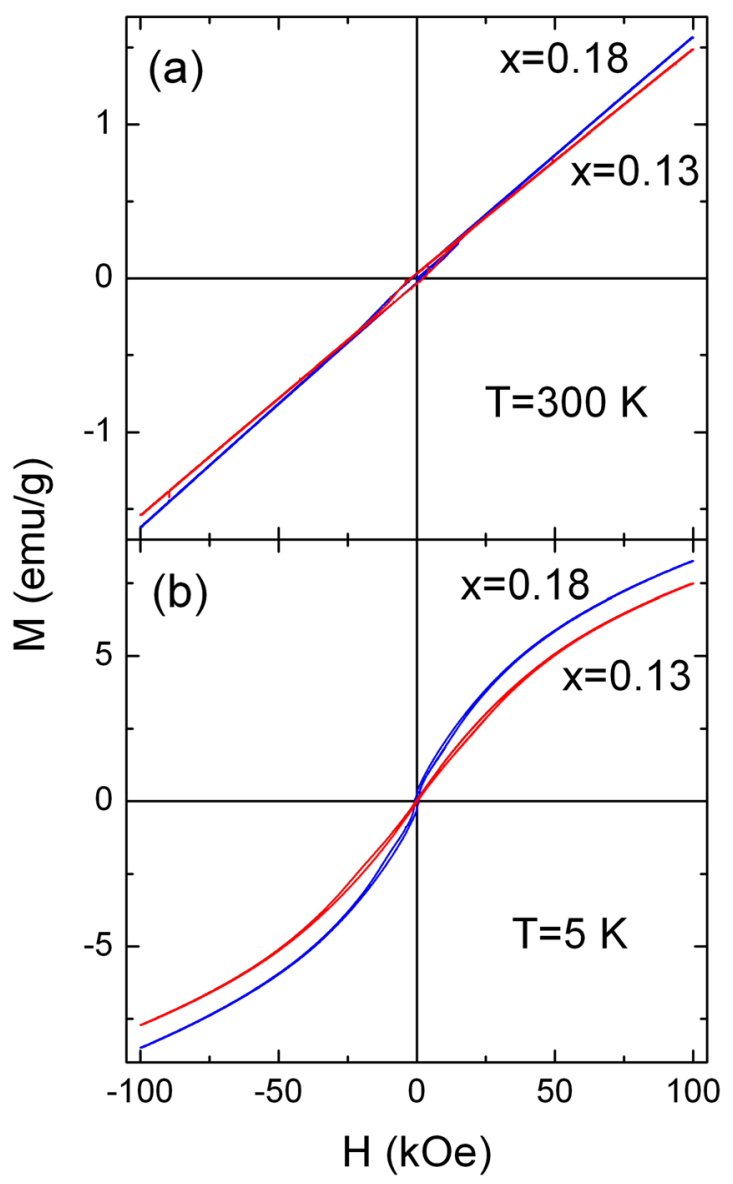

FIG. 6. Field dependences of the magnetization obtained for the $B i_{1-x} \mathrm{La}_{\mathrm{x}}$ $\mathrm{Fe}_{0.6} \mathrm{Mn}_{0.4} \mathrm{O}_{3}(x=0.13,0.18)$ compounds at $\mathrm{T}=300 \mathrm{~K}$ (a) and $\mathrm{T}=5 \mathrm{~K}$ (b). sponsible for appearance of the spontaneous magnetization in the compounds under study and the ferromagnetic superexchange interactions $\mathrm{Mn}^{3+}-\mathrm{O}-\mathrm{Mn}^{4+}$ and $\mathrm{Mn}^{3+}-\mathrm{O}-\mathrm{Mn}^{3+}$ (that are known to be the competitive with the dominant antiferromagnetic $\mathrm{Fe}^{3+}-\mathrm{O}-\mathrm{Fe}^{3+}$ superexchange and tend to stabilize the spin-glass state in the $\mathrm{LaFe}_{1-\mathrm{y}} \mathrm{Mn}_{\mathrm{y}} \mathrm{O}_{3+\delta}$ system ${ }^{24,25}$ ) should also contribute to the resulting magnetic behavior.

$\mathrm{Bi}_{1-\mathrm{x}} \mathrm{La}_{\mathrm{x}} \mathrm{Fe}_{0.6} \mathrm{Mn}_{0.4} \mathrm{O}_{3}(x=0.13,0.18)$ samples demonstrate a complex character of the temperature dependences of the magnetization (Fig. 7) with distinct anomalies both on the zero field cooling (ZFC) and field cooling (FC) curves near $180-190 \mathrm{~K}(x=0.13)$ or $160-170 \mathrm{~K}(x=0.18)$, followed by the rapid glassy-like increase of the magnetization (with decreasing temperature) resembling that one observed for the $\mathrm{LaFe}_{1-\mathrm{y}} \mathrm{Mn}_{\mathrm{y}} \mathrm{O}_{3+\delta}$ compounds with the same $B$-sublattice composition. ${ }^{25}$ In some way, similar behavior was previously found in the polar $\mathrm{BiFe}_{0.75} \mathrm{Mn}_{0.25} \mathrm{O}_{3}$ compound having a rhombohedral structure (S.G. $R 3 \mathrm{c}$ ). ${ }^{16}$ The bulk $\mathrm{BiFe}_{0.75} \mathrm{Mn}_{0.25} \mathrm{O}_{3}$ samples exhibited the same anomaly on the temperature dependence of the magnetization near $170 \mathrm{~K}$ (well below the Neel point of $485 \mathrm{~K}$ ), large increase of the magnetic susceptibility (accompanied by the magnetization reversal) taking place in the low temperature range. ${ }^{16}$ Increased susceptibility at low temperature was also detected upon the magnetic measurements performed for the same samples crashed into powder (in this case, the particles are free to be oriented by the applied magnetic field), however, neither anomaly near $170 \mathrm{~K}$, nor negative magnetization was found. ${ }^{16}$ This behavior should imply orientational character of the related magnetic transformation near $170 \mathrm{~K}$. Orientational magnetic transitions were previously observed in some $\mathrm{Mn}$ free $\mathrm{BiFeO}_{3}$-based perovskites. In the $\mathrm{Bi}_{1-\mathrm{x}} \mathrm{Nd}_{\mathrm{x}} \mathrm{FeO}_{3}$ series, the nonpolar- to- antipolar structural transition, which occurs in the magnetic state, is accompanied by an abrupt $\approx 90^{\circ}$ reorientation of the magnetic moments of $\mathrm{Fe}$ ions. ${ }^{26}$ The coupling between the nuclear and magnetic structures is manifested in a significant magnetization anomaly very similar to that characteristic of our samples. It is interesting to note that reverse

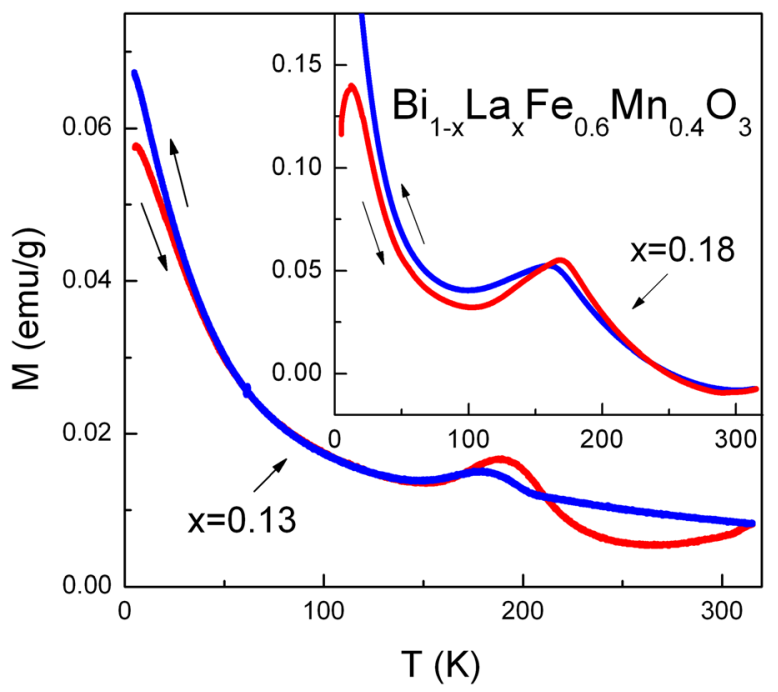

FIG. 7. Temperature dependences of the magnetization for the $\mathrm{Bi}_{1-x} \mathrm{La}_{\mathrm{x}}$ $\mathrm{Fe}_{0.6} \mathrm{Mn}_{0.4} \mathrm{O}_{3}(x=0.13,0.18)$ compounds measured in a field of $500 \mathrm{Oe}$. Red and blue symbols correspond to data obtained in ZFC and FC modes, respectively. 
spin-reorientation transition in the iron sublattice that is not driven by any abrupt changes in the crystal structure of the $\mathrm{Bi}_{1-\mathrm{x}} \mathrm{Nd}_{\mathrm{x}} \mathrm{FeO}_{3}$ samples is observed at low-temperature and manifests itself as the rapid increase of the magnetization (with decreasing temperature) below $50 \mathrm{~K}^{26}$ The complex temperature-induced magnetic behavior seems not to be a property of any distinct structural phase or any particular chemical composition/specific synthesis conditions. Indeed, the anomalous temperature dependence of the magnetization at low temperature $(\sim 100 \mathrm{~K})$ was also observed for the antiferroelectric orthorhombic $\mathrm{BiFe}_{0.75} \mathrm{Mn}_{0.25} \mathrm{O}_{3}$ compound (S.G. Pnam) prepared at high pressure (see supplementary materials in Ref. 16). Moreover, our complementary investigation of the nonpolar $\mathrm{Bi}_{0.6} \mathrm{La}_{0.4} \mathrm{Fe}_{0.6} \mathrm{Mn}_{0.4} \mathrm{O}_{3}$ samples (S.G. Pnma) also found some characteristic anomaly on the ZFC dependence of the magnetization (near $135 \mathrm{~K}$ ). The variety of the compounds and large scattering of the magnetic anomalies temperatures require a systematic approach to investigation of this phenomenon with an involvement of the low temperature neutron diffraction measurements.

\section{CONCLUSIONS}

$\mathrm{X}$-ray diffraction and magnetization measurements of the $\mathrm{Bi}_{1-\mathrm{x}} \mathrm{La}_{\mathrm{x}} \mathrm{Fe}_{1-\mathrm{y}} \mathrm{Mn}_{\mathrm{y}} \mathrm{O}_{3}$ samples with $x=0.13,0.18$ and $y$ approaching the manganese solid solubility limit $(\mathrm{y} \sim 0.4)$ were investigated to follow the effect of the $B$-site doping on the crystal structure and magnetic properties of the polar antiferromagnetic and antipolar weak ferromagnetic phases of the $\mathrm{Bi}_{1-\mathrm{x}} \mathrm{La}_{\mathrm{x}} \mathrm{FeO}_{3}$ series. ${ }^{4,5}$ Both polar [S. G. $R 3 c$, tilting scheme $\left(a^{-} a^{-} a^{-}\right)$] and antipolar [S.G. Pnam, tilting scheme $\left.\left(a^{-} a^{-} c^{+}\right) /\left(a^{-} a^{-} c^{-}\right)\right]$structures characteristic of the $B$-site undoped La-substituted samples were shown to undergo the Mn doping induced phase transformation towards the average Imma $\left(a^{-} b^{0} a^{-}\right)$symmetry. The transformation occurs via the formation of an intermediate structural phase, whose preliminary analysis reveals the regularities formerly reported for the $\mathrm{Bi}_{1-x} \mathrm{La}_{\mathrm{x}} \mathrm{FeO}_{3}$ compounds possessing the incommensurately modulated antipolar structure. Magnetization measurements of the $y=0.4$ compounds found complex temperaturedependent behavior that can be tentatively described as reflecting existence of a spin-reorientation transition in these systems. Spontaneous magnetization characteristic of the samples strongly increases with decreasing temperature, suggesting competitive character of the superexchange interactions in the magnetically-active $B$ sublattice.

\section{ACKNOWLEDGMENTS}

This work was supported by funds from FEDER (Programa Operacional Factores de Competitividade COM-
PETE) and from FCT-Fundação para a Ciência e a Tecnologia under the Project PEst-C/FIS/UI0036/2011, PEst-C/CTM/LA0011/2011, PTDC/FIS/105416/2008, program "Ciência 2008," and Grants SFRH/BPD/42506/2007, SFRH/BPD/39262/2007. The authors would also like to acknowledge the financial support of the BRFFI (Grant T10R-119).

${ }^{1}$ G. Catalan and J. F. Scott, Adv. Mater. 21, 2463 (2009).

${ }^{2}$ C. Ederer and N. A. Spaldin, Phys. Rev. B 71, 060401 (2005).

${ }^{3}$ I. Sosnowska, T. Peterlin-Neumaier, and E. Steichele, J. Phys. C 15, 4835 (1982).

${ }^{4}$ D. A. Rusakov, A. M. Abakumov, K. Yamaura, A. A. Belik, G. Van Tendeloo, and E. Takayama-Muromachi, Chem. Mater. 23, 285 (2011).

${ }^{5}$ I. O. Troyanchuk, D. V. Karpinsky, M. V. Bushinsky, V. A. Khomchenko, G. N. Kakazei, J. P. Araujo, M. Tovar, V. Sikolenko, V. Efimov, and A. L. Kholkin, Phys. Rev. B 83, 054109 (2011).

${ }^{6}$ S. M. Selbach, T. Tybell, M.-A. Einarsrud, and T. Grande, Chem. Mater. 21, 5176 (2009).

${ }^{7}$ V. A. Khomchenko, I. O. Troyanchuk, M. I. Kovetskaya, M. Kopcewicz, and J. A. Paixão, J. Phys. D: Appl. Phys 45, 045302 (2012).

${ }^{8}$ V. A. Khomchenko, I. O. Troyanchuk, M. I. Kovetskaya, and J. A. Paixão, J. Appl. Phys. 111, 014110 (2012).

${ }^{9}$ V. A. Khomchenko, I. O. Troyanchuk, D. V. Karpinsky, and J. A. Paixão, J. Mater. Sci. 47, 1578 (2012).

${ }^{10}$ S. Karimi, I. M. Reaney, Y. Han, J. Pokorny, and I. Sterianou, J. Mater. Sci. 44, 5102 (2009).

${ }^{11}$ V. A. Khomchenko, J. A. Paixão, V. V. Shvartsman, P. Borisov, W. Kleemann, D. V. Karpinsky, and A. L. Kholkin, Scr. Mater. 62, 238 (2010).

${ }^{12}$ V. A. Khomchenko, J. A. Paixão, B. F. O. Costa, D. V. Karpinsky, A. L. Kholkin, I. O. Troyanchuk, V. V. Shvartsman, P. Borisov, and W. Kleemann, Cryst. Res. Technol. 46, 238 (2011).

${ }^{13}$ J. Rodríguez-Carvajal, Physica B 192, 55 (1993).

${ }^{14}$ A. M. Glazer, Acta Crystallogr., Sect. A: Cryst. Phys., Diffr., Theor. Gen. Crystallogr. 31, 756 (1975).

${ }^{15}$ T. Stevenson, T. P. Comyn, A. Daoud-Aladine, and A. J. Bell, J. Magn. Magn. Mater. 322, L64 (2010).

${ }^{16}$ A. A. Belik, A. M. Abakumov, A. A. Tsirlin, J. Hadermann, J. Kim, G. Van Tendeloo, and E. Takayama-Muromachi, Chem. Mater. 23, 4505 (2011).

${ }^{17}$ M. Azuma, H. Kanda, A. A. Belik, Y. Shimakawa, and M. Takano, J. Magn. Magn. Mater. 310, 1177 (2007).

${ }^{18}$ D. J. Singh, M. Ghita, M. Fornari, and S. V. Halilov, Ferroelectrics 338, 73 (2006).

${ }^{19}$ O. Dieguez, O. E. Gonzalez-Vazquez, J. C. Wojdel, and J. Iniguez, Phys. Rev. B 83, 094105 (2011).

${ }^{20}$ D. P. Kozlenko, A. A. Belik, A. V. Belushkin, E. V. Lukin, W. G. Marshall, B. N. Savenko, and E. Takayama-Muromachi, Phys. Rev. B 84, 094108 (2011).

${ }^{21}$ R. D. Shannon, Acta Crystallogr., Sect. A: Cryst. Phys., Diffr., Theor. Gen. Crystallogr. 32, 751 (1976).

${ }^{22}$ I. Dzyaloshinsky, J. Phys. Chem. Solids 4, 241 (1958).

${ }^{23}$ T. Moriya, Phys. Rev. 120, 91 (1960).

${ }^{24}$ O. F. de Lima, J. A. H. Coaquira, R. L. de Almeida, L. B. de Carvalho, and S. K. Malik, J. Appl. Phys. 105, 013907 (2009).

${ }^{25}$ K. De, R. Ray, R. N. Panda, S. Giri, H. Nakamura, and T. Kohara, J. Magn. Magn. Mater. 228, 339 (2005).

${ }^{26}$ I. Levin, M. G. Tucker, H. Wu, V. Provenzano, C. L. Dennis, S. Karimi, T. Comyn, T. Stevenson, R. I. Smith, and I. M. Reaney, Chem. Mater. 23, 2166 (2011). 